\title{
DEL MOTIVO DE CONSULTA A LA DEMANDA EN PSICOLOGÍA
}

FROM REASON FOR CONSULTATION TO DEMAND IN PSYCHOLOGY

\section{RESUMEN}

Mientras que el concepto de «motivo de consulta» refiere a una descripción de síntomas o problemas objetivos, el concepto de «demanda» implica el reconocimiento de una necesidad subjetiva y el deseo de pedir ayuda. Para poder actuar en psicología es necesario que el motivo de consulta pueda expresarse en forma de una demanda.

Palabras clave: Motivo de consulta, demanda, psicología

\section{ABSTRACT}

Whereas the «consultation motive» concept reports a description of symptoms or objective problem, the «demand» concept involves the recognition a subjective necessity and the ask aid desire. To be able to operate in psychology is necessary that consultation motive can to express in shaped like a demand.

Key-words: Consultation motive, demand, psychology 


\section{EL MOTIVO DE CONSULTA EN EL DIAGNÓSTICO PSICOLÓGICO}

La premura por concretar un diagnóstico psicopatológico puede hacer olvidar la importancia que tiene el motivo concreto de consulta del paciente. Erróneamente se puede concebir el motivo de consulta, es decir, la causa que ha estimulado al paciente a solicitar la visita, simplemente como la puerta que abre paso a la exploración de los signos o síntomas que permitirán concretar un diagnóstico psicopatológico. Y en esta línea, una vez formulado el diagnóstico, ya sea sintomático, estructural, conductual, relacional, etc., no cabe más que plantear una terapéutica coherente, relegando el motivo de consulta a un segundo nivel de importancia cuando no directamente al olvido. Tal vez este modo de proceder se deba a la influencia que históricamente ha ejercido en la psicología el método clínico practicado por la medicina, que prima la importancia de los rasgos fenomenológicos. Entre los métodos clínicos utilizados por ambas disciplinas existen nexos comunes puesto que comparten un mismo campo de trabajo -la patología-, pero también diferencias obvias, ya que su objeto de estudio es distinto: lo somático y lo psíquico.

En este artículo intentaré demostrar, en primer lugar, que en psicología no puede disociarse el motivo de consulta del diagnóstico psicopatológico, y en segundo, que más allá del motivo de consulta es necesario averiguar cuál es la demanda implícita en él, puesto que la demanda habla de la motivación y los intereses subjetivos del paciente a implicarse en la solución de su malestar.

\section{LOS «AGENTES TERAPÉUTICOS» EN PSICOLOGÍA.}

Por «agente terapéutico» podemos entender el elemento que toma contacto contacto con una determinada estructura del individuo, biológica en el caso de la medicina y psicológica en el caso de la psicología, consiguiendo modificarla y produciendo como resultado las mejorías clínicas esperadas por el médico o el psicólogo respectivamente.

En cirugía podemos considerar que el «agente terapéutico» es el médico que practica la intervención quirúrgica. El paciente, anestesiado total o parcialmente, aguarda a que el médico pueda realizar su trabajo. En farmacología el «agente terapéutico» es la sustancia química que contiene el fármaco, con capacidad de incidir en el metabolismo provocando los cambios esperados por el médico. En psicología el agente terapéutico, es decir, el elemento encargado de modificar una determinada estructura psicológica es, en función de las distintas escuelas, la interpretación de un contenido inconsciente del paciente, la adopción de un nuevo estilo cognitivo, de una manera más saludable de posicionarse ante un familiar, de una conducta más adaptada a las circunstancias, los registros diarios de pensamientos y conductas, etc.

La diferencia fundamental entre los agentes terapéuticos utilizados en medicina y en psicología es que, en el primer caso el agente terapéutico puede actuar sin 
necesitar la presencia del «paciente como sujeto», mientras que en el segundo eso es imposible. El concepto de «paciente como sujeto» pretende hacer referencia a los componentes subjetivos del individuo que consulta: el paciente puede entenderse como un «objeto» que sufre, sobre el que se va a aplicar un tratamiento para aliviarlo, pero también como un «sujeto», con un grado mayor o menor de responsabiliadad en su sufrimiento y de implicación en la posibilidad de su curación (1).

En medicina el agente terapéutico actúa en el «paciente-objeto», es decir, en su estructura fisiológica. El «paciente-sujeto» es un mero espectador de la acción del agente terapéutico, puesto que ésta se puede llevar a cabo sin ningún grado de participación por parte de él. En cirugía por ejemplo, el paciente facilita que el médico actúe en él, como «paciente-objeto», mientras que como «paciente-sujeto» puede permanecer ausente, dormido o anestesiado. Tal condición permite que en medicina se pueda incluso actuar a espaldas del «paciente-sujeto» $(2,3)$. Es el caso, por ejemplo, del paciente que se encuentra en un estado delirante grave con riesgo suicida al que se le consigue suministrar un sedante sin que el lo sepa o incluso en contra de su voluntad.

Los agentes terapéuticos de la psicología, en cambio, sólo pueden actuar en la medida que tienen en cuenta la interrelación entre el «paciente-sujeto» y el «paciente-objeto». Por ejemplo, cuando se dice que el estado depresivo de un paciente se debe a que concentra su atención exclusivamente en las cosas negativas que le suceden se está apelando a que el «paciente-objeto» está padeciendo un cuadro depresivo debido a que el «paciente-sujeto» concentra su atención en pensamientos negativos. 0 bien, cuando se le explica a un paciente que practique una determinada técnica de relajación en un ambiente tranquilo y libre de exigencias por parte de su entorno se está haciendo referencia a que esa persona debe procurar esperar -como «sujeto»-, a sentirse tranquila -como «objeto»-, para poder aplicar -como «sujeto»-, en él mismo -como «objeto»-, la técnica terapéutica.

Independientemente del modo de entender la psicología al que obedezcan, la existencia de los agentes terapéuticos presupone la participación directa de la parte subjetiva del paciente, del «paciente-sujeto». Utilizando los ejemplos anteriores, ningún paciente puede de manera efectiva oír y reflexionar acerca de una interpretación de su psicoanalista, anotar pensamientos y conductas en un registro, practicar ejercicios conductuales, etc., si está dormido o anestesiado, o simplemente, si en realidad no desea curarse.

Por consiguiente, mientras que en medicina la actuación del médico puede dirigirse directamente al «paciente-objeto» en ausencia del «paciente-sujeto», en psicología la actuación del psicólogo sólo podrá incidir en el «paciente-objeto» si es mediatizada por la participación del «paciente-sujeto». Más concretamente, en psicología cualquier tipo de tratamiento sólo puede llevarse a cabo si el paciente expresamente lo desea y se compromete. 
Es decir, en el momento de plantear un tratamiento psicoterapéutico el psicólogo debe tener en cuenta que el éxito dependerá no sólo de lo capaz que se sienta para llevarlo correctamente a cabo, sino también de lo motivado que esté el paciente en realizarlo.

Por tanto, más allá del diagnóstico psicopatológico construído a partir de la clínica manifiesta y observable, el psicólogo debe preguntarse cuáles son las motivaciones del paciente en cuanto a su bienestar personal o psicológico, es decir, qué es lo que realmente desea en relación a sí mismo y qué está dispuesto a hacer para conseguirlo. Debe preguntarse: qué es lo que le ha hecho venir a consultar y qué es lo que desea conseguir con ello.

Otro rasgo diferencial entre las características de los «agentes terapéuticos» de la medicina y la psicología tiene que ver con el dolor, sufrimiento o malestar que su acción añade. En farmacología la penetración del compuesto químico en el organismo se hace de modo imperceptible para el paciente. En el caso de la psicología, sea cual sea el tipo de tratamiento que se practique, la actuación de los «agentes terapéuticos» presupone la aproximación del paciente, ya sea mental o físicamente a aquello que le hace sufrir, con la consecuente carga de dolor.

Es lógico pensar que el paciente sólo estará dispuesto a asumir esa sobrecarga de dolor o displacer añadido del «agente terapéutico» en la medida que perciba que efectivamente incide en aquello de sí mismo que más profundamente siente que le molesta. Por este motivo, en el momento de interrogar por el motivo de consulta, el psicólogo debe cuestionarse si más allá de lo manifiesto puede existir otra motivación más profunda.

\section{MOTIVO DE CONSULTA MANIFIESTO VS. MOTIVO DE CONSULTA LATENTE}

El motivo de consulta puede tener que ver con la clínica objetivable pero también con una inquietud subjetiva que el paciente no sepa o atreva a manifestar. Por ejemplo, cuando un paciente explica haber decidido poner fin a un intenso cuadro psicopatológico que hace meses o años padece, la clínica manifiesta justifica el motivo de consulta pero no informa de cómo la persona ha conseguido soportar ese malestar durante todo ese tiempo, por qué ha tardado tanto en decidirse a consultar ni por qué lo ha hecho en ese preciso momento de su vida. Tales interrogantes pueden hablar de otro tipo de motivaciones añadidas o distintas a liberarse de los rasgos psicopatológicos evidentes. 0 cuando una persona con problemas de adicción a una determinada sustancia tóxica acude a consultar presionado por sus familiares, no necesariamente el motivo de consulta es vencer la adicción, sino tal vez, liberarse de la exigencia de aquéllos sin tener que dejar de consumir. Lo mismo ocurre en las personas que acuden a consultar obligadas por una resolución judicial a consecuencia de un delito, en quienes no hay conciencia de enfermedad y cuyo único objetivo es conseguir una disminución de condena. 
Por tanto, es evidente que a veces el motivo que el paciente alega como justificante de su consulta, o que el psicólogo presupone a partir de la clínica, es decir, lo que se denomina «motivo de consulta manifiesto o explícito» no es el motivo que profundamente ha estimulado al paciente a consultar, lo que se denomina «motivo de consulta latente o implícito» (4).

\section{- Motivo de consulta manifiesto}

El motivo de consulta manifiesto obedece a la interpretación que el paciente hace de su malestar, que está mediatizada por la información médica o psicológica que dispone, su capacidad para entenderla adecuadamente, el haber sufrido experiencias previas iguales o semejantes, el imaginario socio-cultural en el que vive, etc. (5). Por ejemplo un paciente, Miguel, alega que ha acudido a consultar porque no puede controlar sus enfados, que a veces le llevan a sentirse muy agresivo con las personas de su entorno. Fue su esposa quien le recomendó visitarse a raíz de una discusión conyugal, pero él también cree darse cuenta de la magnitud de su problema. Explica que ya en una ocasión estuvieron a punto de despedirle de un empleo a raíz de una pelea con un compañero. Miguel entiende que sufre un problema de control de los impulsos y que necesita ayuda profesional. Pero podemos preguntarnos si realmente ha venido a consultar por este motivo, si efectivamente su facilidad para enojarse es lo que más le preocupa de sí mismo. Interrogado, Miguel sigue explicando que durante muchos años sus allegados ya le han advertido de su carácter irritable pero que es sobre todo ahora, su mujer, la que más ha insistido sobre ello. Miguel reconoce que su vida social y familiar puede complicarse y ve la necesidad de ponerle solución. No obstante, hasta este punto, lo que sabemos del motivo de consulta de Miguel es la interpretación que sus allegados han hecho del aspecto manifiesto de su problema: su carácter violento. Pero desconocemos si verdaderamente él está de acuerdo con tal interpretación. Que la haya adoptado como propia no quiere decir necesariamente que crea en ella. Entre lo que Miguel escucha que los demás opinan de él y lo que él realmente siente que le pasa puede existir una nube de confusión. El psiquismo está constituído por una compleja interrelación de ideas y sentimientos referidos a uno mismo y al entorno, que tienen que ver con el presente, el pasado y el futuro, mediatizados por la experiencia y la relación con los demás y el universo circundante. Ver las cosas claras a través de este entramado no siempre resulta fácil.

\section{- El motivo de consulta latente}

La diferencia fundamental entre los conceptos «motivo de consulta manifiesto» y «motivo de consulta latente» es que el segundo hace referencia a la percepción subjetiva del motivo de consulta. El paciente del ejemplo anterior, Miguel, al seguir interrogándole pudo reconocer que sus enfados tenían que ver con la dificultad a soportar la más mínima crítica, el más mínimo cuestionamiento que pudieran hacerle 
de determinados aspectos de su carácter. Sin duda que ha acudido porque sufre, pero no parece ser su conducta agresiva el principal motivo de ello, aunque reconozca la gravedad de sus consecuencias. Al intentar aclarar el motivo de consulta el psicólogo averigua que el sufrimiento de Miguel gira entorno a no poder soportar dudar acerca de según qué aspectos de sí mismo. La conducta agresiva, sólo es su aspecto manifiesto. La dificultad para tolerar pensar que ha hecho o hace algo mal es lo que le desencadena su ira. Ése es el motivo de consulta latente (6).

Situaciones en las que es probable la existencia de un motivo de consulta latente distinto al manifiesto

a) El motivo de consulta manifiesto parece irracional o extraño en relación al contexto en que se produce.

Una paciente, Laura, acudió a consultar excusándose de que lo único que deseaba era que la aconsejara algún libro de autoayuda para resolver un problema que le afectaba, que calificaba de simple y sin importancia, que no merecía el tiempo que ningún especialista puediera dedicarle. Al parecer, la misma petición había formulado al médico de cabecera y al psiquiatra que la habían atendido anteriormente pero, según Laura, éstos no conocían ningún título y decidieron derivarla. El problema al que se refería consistía en una serie de desacuerdos «sin importancia» en algunos aspectos de la relación con su esposo. A pesar de aceptar que esos desacuerdos podían ser consecuencia del carácter autoritario de ella, como ya varios amigos le habían sugerido, consideraba que en realidad era a su marido a quien más le afectaba, que respondía acobardándose.

Hasta este punto parece claro que el motivo de consulta de Laura es ser aconsejada por un psicólogo a leer algún libro de autoayuda especializado en problemas de pareja, pero si tenemos en cuenta que el médico de cabecera y el psiquiatra que la habían atendido anteriormente prefirieron derivarla a la consulta de un psicólogo, mejor que darle la dirección de un librero, es que algún motivo clínico debieron considerar. Por otro lado, si Laura aguardó el protocolo «médico de cabecera-psiquiatra-psicólogo» con sus respectivos días, semanas o meses de espera antes de ser atendida por cada uno de ellos sería porque tal vez detrás de la demanda de un libro de autoayuda se escondía otra más angustiante. Efectivamente, al interrogarala detenidamente por su problema reveló que esos desacuerdos «sin importancia» que a veces existían entre ella y su esposo eran consecuencia, por ejemplo, de una inversión de 24.000 euros que su marido había hecho en un negocio que ella no había autorizado por considerar que era poco seguro y porque además, aún tenían que devolver otra importante deuda que hacía años habían contraído, todo ello teniendo la responsabilidad de cuidar y educar a tres hijos, de siete, cuatro y dos años de edad respectivamente. Llegado a este punto, la paciente pudo reconocer que, independientemente de cómo reaccionara su esposo al carácter hostil de ella, lo cierto es que ella también sufría por el carácter de él. Esconder esta preocupación detrás de la petición de un libro 
de autoayuda puede entenderse como un intento de minimizar la importancia que daba a los problemas que tenía con su esposo, con el fin de ocultarse a sí misma el dolor y/o la rabia que su impotencia ante ellos le producía. Pretender resolver tales problemas mediante un libro de autoayuda era algo así como querer vaciar el agua de una piscina con una cuchara, no reconociendo que allí hay agua suficiente como para poder ahogarse.

b) El paciente muestra poca convicción o preocupación por el problema que manifiesta estar sufriendo, lo plantea de forma contradictoria o muestra pocos detalles del mismo.

Sandra, de 20 años, empezó la visita explicando que consultaba con la finalidad de que el psicólogo le brindara algún consejo para resolver el «pánico» que le producía encontrarse con chicos o chicas de su edad, ya que siempre temía sentirse critidada por ellos. Con estas palabras creí entender que padecía un problema importante de aislamiento social, pero la escasa angustia que era capaz de distinguir en ellas no se correspondía con la gravedad de la situación que yo imaginaba. Sandra continuó diciendo que recientemente había roto con un grupo de amigos y que había empezado a salir con dos amigas. Por tanto -seguí pensando- no existía en realidad ninguna situación de aisalmiento social o, al menos, de la gravedad que había yo había presupuesto, ya que Sandra era capaz de dejar un grupo de amigos y buscarse otro. Eso quedó reafirmado cuando explicó que estaba repitiendo segundo de bachillerato. Es decir, era capaz de seguir un curso escolar junto con otros compañeros. A continuación detalló diversas situaciones en las que se había sentido criticada e insultada por chicos y chicas de su edad y que por ello, a los dieciséis años, durante las vacaciones escolares permaneció tres meses sin salir de casa, «Ni siquiera para ir a buscar el pan, por miedo a encontrarme a alguien», precisó. Pero esta extraña fobia terminó al iniciar el nuevo curso, al que pudo asistir con normalidad desde el principio. Por tanto, la dificultad para poder encontrarse con chicos y chicas de su edad no parecía ser la verdadera causa de la consulta. Con el fin de aclarar la confusión le pregunté qué tipo de consejo esperaba recibir de mí. Respondió que yo debía explicarle cómo hacer nuevas amistades o cómo relacionarse con la gente, lo que no resolvió ninguna de mis dudas. Seguidamente le pregunté por qué creía que la gente la criticaba. «Creo que es por mi aspecto físico; no le gusto a la gente», contestó. Esta respuesta sirvió para dar paso a lo que reconocí como una preocpación más auténtica y profunda: «No me gusto ni a mí. Mi cara no me gusta. Ahora me encuentro mejor porque me han hecho la cirugía maxilofacial; antes no podía ni sonreír». «¿No te gusta el aspecto de tu cara?», le pregunté. «Tampoco mi carácter. Tengo un carácter pesimista total. Cuando me dicen de ir al cine, siempre pienso que la película no me va a gustar, o que me voy a encontrar con algún grupo de chicos que me incriminarán». Antes de finalizar la entrevista pudo añadir otro dato más: 
«Tengo muy mala leche; la descargo con mi familia y conmigo». Por tanto, lo que verdaderamente preocupapa a Sandra era la intolerancia y el desprecio que sentía por sí misma, que proyectaba en los chicos y chicas de su edad, contra lo cual nada podía hacer, y que indudablemente constituía el germen de su rabia y malhumor. Consideré que éste era el motivo de consulta implícito o latente, el que era necesario abordar.

c) El paciente dice consultar por un trastorno o problema que hace mucho tiempo que padece.

En ocasiones el motivo de consulta refiere a un problema antiguo, tal vez cronificado. En sí mismo, ese motivo de consulta no justifica por qué el paciente ha decidido finalmente ponerle solución en ese momento de su vida. Si se interroga sobre ello tal vez se descubran otras motivaciones que expliquen esa circunstancia.

Elvira, una paciente de 36 años, explica en su primera visita que acude por un estado depresivo que padece desde hace muchos años. Nunca antes había consultado por ello pero ahora ha decidido intentar solucionarlo. Al parecer, ese cuadro depresivo se inició después de nacer su segundo hijo, hace más de 10 años. Desde entonces, explica Elvira, nunca más ha vuelto a ser la persona de antes, desenfadada, optimista, etc. Concreta que su cuadro depresivo consiste en sentimientos generalizados de apatía, desánimo, ausencia de ganas de vivir, cansancio, etc. Se trata sin duda de un cuadro depresivo de larga evolución, desencadenado probablemente por el nacimiento de su segundo hijo. Si el motivo de consulta se plantea de este modo cabe pensar que algo conflictivo despertó en Elvira el nacimiento de su segundo hijo que aún no ha podido solucionar. Pero, ¿por qué ha esperado 10 años en venir a consultar?, ¿por qué acude justo ahora? Interrogada sobre ello Elvira explica que no podía seguir soportando por más tiempo esa situación de desánimo y falta de ganas de vivir. Le pregunto qué cree que ha sucedido para que ahora sienta que no puede soportar más esa situación personal de desánimo y falta de ganas de vivir. Elvira responde que es una situación insostenible que afecta negativamente al resto de su familia. Insatisfecho aún, le sigo preguntando cuál cree que ha podido ser la causa que la ha llevado a considerar ahora que su malestar personal puede afectar al resto de su familia. Al concretar la pregunta de este modo Elvira aclara: «Es que ahora, mi hija mayor, está mostrando los mismos síntomas que yo tenía cuando nació el hijo pequeño». Por tanto, la causa que ha llevado a Elvira a consultar no ha sido simplemente su cuadro depresivo sino la preocupación de que a su hija le pase lo mismo que a ella. Cuando un paciente acude a consultar por un trastorno o problema que parece ya cronificado, habitualmente existe la urgencia de otro motivo de consulta de tipo latente. 


\section{DEL MOTIVO DE CONSULTA A LA DEMANDA EN PSICOLOGÍA}

Anteriormente he señalado que la acción de los «agentes terapéuticos» implicados en psicología está mediatizada por la parte subjetiva del paciente, es decir, que si no existe una petición de ayuda, un deseo de dejarse ayudar, el psicólogo no tiene posibilidad de actuar. También he señalado que el paciente sólo estará dispuesto a asumir la sobrecarga de dolor añadido que conlleva la acción de los «agentes terapéuticos» propios de la psicología en la medida que perciba que inciden en aquello de sí mismo que efectivamente siente que le duele o hace sufrir. Si el paciente es capaz de reconocer las características de su dolor y entender el significado latente de su consulta, automáticamente podrá sentir aquello herido de sí mismo como algo que necesita remedio. Una vez sentida la necesidad, podrá formular al psicólogo una petición de ayuda, es decir, una demanda $(7,8)$.

La diferencia entre motivo de consulta y demanda es que mientras lo primero puede limitarse a la descripción de un conjunto de signos, síntomas o problema de naturaleza objetiva, el concepto de demanda, que obedece a la transitividad, supone la expresión de un deseo, la petición explícita de ayuda. En psicología, por la naturaleza de los «agentes terapéuticos» que emplea, no se puede trabajar a partir simplemente del motivo de consulta, puesto que el motivo de consulta es la expresión en bruto del padecer del paciente. En psicología, el motivo de consulta debe poderse reformular en otra expresión que sea practicable, es decir, en una demanda $(9,10,11,12)$.

\section{CARACTERÍTICAS DE LA EXPRESIÓN DE LA DEMANDA EN PSICOLOGÍA}

Para que el motivo de consulta sea practicable para el psicólogo es necesario que pueda reformularse en una demanda con las siguientes características:

1. Como un problema: En psicología, excepto en el caso de las técnicas conductistas puras, no es suficiente delimitar el motivo de consulta a una descripción de síntomas puesto que directamente sobre ellos no se puede actuar. Se hace sobre las supuestas causas que los han generado, ya sea que se trate de pensamientos distorsionados, relaciones desadaptativas, resistencias inconscientes, etc. En realidad la psicofarmacología tampoco interviene directamente sobre el síntoma sino que lo hace sobre lo que considera sus causas, es decir, las alteraciones en determinadas reacciones metabólicas del organismo. Pero, a diferencia de la psicología, la psicofarmacología se fundamenta en una teoría muy concreta basada en la fisiología, común a todas las personas, que permite decidir el tipo de agente químico que se debe inocular en el organismo a partir del análisis fenomenológico del cuadro sintomático. En psicología, los mismos síntomas o cuadros psicopatológicos pueden deberse a situaciones y problemas totalmente distintos en función de cada individuo. 
2. Como un problema personal, con uno mismo o con los demás: A menos de que acuda el grupo familiar, lo cual se tratará más adelante en este artículo, el psicólogo sólo puede intervenir directamente en la persona que consulta. Puede brindar pautas o consejos para que el paciente los aplique en su relación con otras personas pero es a ese paciente a quien se los explica, para que él las ponga en práctica. La demanda tiene que estar centrada en lo que al paciente le preocupa y le hace sufrir. Es decir, tiene que estar explicitada como un problema personal. Podemos entender un problema psicológico como un conflicto de la persona consigo misma o con los demás. Por ejemplo, la persona que padece agorafobia es alguien que desea poder acudir sola a lugares públicos o concurridos, pero no se ve capaz de hacerlo, lo que le genera un importante malestar personal. 0 también podemos entender que una persona tiene un problema psicológico cuando no consigue adaptarse correctamente a las situaciones sociales. Por tanto, para que la demanda que el paciente formula sea practicable por el psicólogo, debe estar concretada en forma de un problema propio, personal o interrelacional.

3. Un problema concreto: A veces el paciente tiene dificultad en concretar el problema o problemas por los que consulta, por el propio dolor que ellos le infligen. Hablar de un problema de manera vaga e impersonal es una forma de apartarse de ese dolor, de escabullirlo. Pero, al contrario, el psicólogo necesita aproximarse al problema lo máximo posible, para poderlo observar en todas sus dimensiones y decidir la mejor manera de abordarlo. No es suficiente, por ejemplo, que el paciente explique que acude a consultar porque no puede dormir. Debe aclarar en qué situaciones no puede dormir, desde cuándo no puede dormir, cuántas horas duerme, en qué momentos del día, etc. De este modo es posible averiguar, por ejemplo, que el insomnio se inició cuando en la empresa le cambiaron su turno de trabajo y llegaba a casa pasadas las 10 de la noche en lugar de a las 5 de la tarde, como ocurría antes de que modificaran su turno; llegar a casa a las diez de la noche supone cenar inmediatamente y poco después acostarse, pero no conciliar el sueño hasta las 3 de la madrugada; el problema es que a las 7 ya se despierta, que era la hora habitual de levantarse los días laborables hasta entonces; además, no puede dormir la siesta como había hecho siempre, porque a la una y media del mediodía ya tiene que dirigirse de nuevo al trabajo. Explicado de este modo, podemos pensar que es normal que el paciente no pueda conciliar el sueño cuando se acuesta, porque acaba de cenar y además hace poco que ha llegado del trabajo y no ha tenido tiempo de olvidarse de él y de sus problemas. Por otro lado, si durante muchos años se ha levantado a una misma hora para ir a trabajar es lógico también que a esa hora le suene una especie de despertador interno que le interrumpa el sueño. Si además, el paciente explica que él se negó a aceptar ese turno porque le priva de estar con su familia por la tarde pero que finalmente la empresa se lo impuso, podemos inferir que a las dificultades nor- 
males que supone acostumbrar el organismo a otro horario de sueño se suma el hecho de tener que hacerlo por la fuerza y a disgusto. Por todo ello, el problema de insomnio de este paciente puede quedar concretado del siguiente modo: $E l$ paciente padece insomnio porque no se acostumbra a seguir durmiendo más allá de las siete de la mañana, tal vez, porque ésa es la hora en que realmente él querría ir a trabajar.

4. Un problema que el paciente siente necesidad de resolver: Cuando se interroga al paciente acerca de su motivo de consulta puede ocurrir que éste se limite a enumerar los fenómenos psicopatológicos que le suceden, pero que a su vez muestre indiferencia hacia los mismos, como si en realidad no le estuviera pasando a él. Esta aparente falta de contacto con el malestar que a su vez describe es propio de la belle indifférence de la histeria, pero también puede ser resultado de mecanismos de defensa más o menos conscientes, cuyo fin es mantener el sufrimiento lo más alejado posible. Para plantear un tratamiento psicoterapéutico no basta con que el paciente se limite a explicar lo que le ocurre sino que ha de demostrar que verdaderamente aquello le preocupa. Para que el paciente consiga formular una demanda es necesario, por un lado, que tome plena consciencia del malestar que le ocasionan aquellos síntomas o problemas que describe en el motivo de consulta y, por otro, que desee verdaderamente librarse de ellos. Antes de iniciar un tratamiento psicoterapéutico es necesario que en su demanda el paciente sea capaz de reconocer y explicitar claramente esta doble necesidad. Por esta razón siempre es necesario indagar más allá del motivo de consulta manifiesto.

5. Un problema por el que el paciente solicita ayuda: Pedir ayuda no siempre es algo fácil y cómodo puesto que supone descubrir ante otra persona las propias carencias (13). Se trata sin duda de una situación en que la autoimagen, orgullo o narcisismo se pueden ver debilitados y dar lugar a sentimientos de inferioridad y vergüenza. Aunque la persona que consulta sepa que el psicólogo es un profesional dispuesto a ayudarle y con capacidad para entenderle, no puede evitar reconocerlo también como otro ser humano semejante a él. Pero sin esta petición de ayuda el psicólogo no puede trabajar, como anteriormente ya he señalado al referir que su intervención está mediatizada por el deseo del paciente. Aunque pueda resultar doloroso para el paciente, la demanda siempre tiene que estar formulada como una petición de ayuda. No es necesario que explícitamente el paciente lo exprese, pero sí debe quedar registrada implícitamente, de modo que si el psicólogo le dijera: «Es decir, usted ha venido a consultar para que yo le ayude a...», el paciente debería responder afirmativamente. 


\section{DEL MOTIVO DE CONSULTA A LA DEMANDA CUANDO ACUDE UNA PAREJA 0 UNA FAMILIA}

Cuando una pareja o una familia consulta es porque la relación entre ellos se ha deteriorado. Los miembros que acuden suelen ser aquellos que son capaces de reconocer su implicación en el problema y/o están interesados en logar algún cambio. Pero, generalmente, más allá del motivo de consulta común, existen los diversos motivos de consulta de cada uno de los miembros, que corresponden a su visión personal del problema. Si el psicólogo desea realizar un tratamiento familiar y no un conjunto de intervenciones individuales primero deberá conseguir que todos los miembros sean capaces de establecer una misma demanda, a partir de la cual poder trabajar conjuntamente. Por tanto, la demanda debe estar formulada como un problema relacional en la que todos los miembros que acuden a consultar quedan implicados de la misma forma.

Los dos miembros de una pareja, Lucas y Silvia, acuden a consultar debido a la angustia de ella, de cuarenta años, por el rumbo que desde hace mucho tiempo está tomando la relación con él, quince años mayor. Tienen un hijo de seis años. Ella cree que él tiene un problema con la bebida pero que no reconoce. Explica que en casa ingiere un volumen de alcohol considerable y que además se ausenta para ir al bar, del que regresa mareado y sin ganas de comer. Desde hace varios meses está perdiendo peso progresivamente pero él no quiere ir al médico. Sospecha que Lucas puede estar enfermando y por ese motivo ella acudió al médico de cabecera, quien solicitó una analítica para realizar tan pronto como Lucas quisiera, pero de momento se niega. Lucas atribuye el problema de pareja a una causa distinta: Silvia está obsesionada con la idea de que él bebe. Cuando baja al bar es para estar con los amigos pero el alcohol ni lo prueba, dice. La familia de él, continúa, también piensa que es Silvia que se está obsesionando innecesariamente por la salud de él. Silvia contradice estas últimas palabras del marido y afirma que en realidad la familia de él piensa lo mismo que ella. Al parecer, ha sido la esposa quien ha insistido en pedir consulta al psicólogo. Lucas ha acudido obligado, para que ella «no se pusiera más pesada de lo que ya lo está», afirma el esposo. Durante la entrevista, Silvia habla con coherencia, razonando lo que explica. En la expresión de sus palabras puedo adivinar la angustia que la situación que describe le ocasiona. Lucas habla con frialdad, sólo para defenderse de las acusaciones de su esposa, y sus razonamientos, cuando los hay, se contradicen. Su único argumento es que Silvia está exageradamente obsesionada. Con la finalidad de ordenar las ideas que habían ido surgiendo decidí mostrarles mi opinión. Les expliqué que yo no podía saber quién de los dos poseía razón en lo que decían y que por tanto, no tenía más remedio que creer a los dos. Les dije que me parecía que había un punto de acuerdo entre los dos que era muy claro: los dos querían seguir juntos sintiéndose bien el uno al lado del otro. Ambos me miraron y asintieron al unísono. Seguí diciéndoles que, no obstante, prácticamente no existían otros puntos de acuerdo, de encuentro entre 
ambos que les permitieran empezar a trabajar conjuntamente en resolver lo que les ocurría: Silvia atribuía el malestar de la pareja a que Lucas bebía demasiado, pero Lucas negaba esta afirmación y consideraba que era producto de la obsesión de Silvia. Por tanto, tal vez lo que realmente planteaban, seguí diciendo, no era cómo seguir conviviendo juntos sino cómo poderse separar y continuar queriéndose, teniendo en cuenta que de su capacidad de aprecio mutuo dependía el bienestar de un niño de seis años. A continuación la esposa explicó que la idea de la separación cada vez la veía más próxima pero le atormentaba pensar que si lo abandonaba él continuaría bebiendo y despreocupándose por su salud hasta terminar con mucha probabilidad gravemente enfermo. Lucas escuchó sin decir nada. De nuevo retomé la palabra y me dirigí a la esposa insistiendo en que yo tenía que creer lo que los dos me decían, y por tanto, si ella decía que su marido estaba en una situación de mucho riesgo para su propia salud debido a que bebía descontroladamente, era evidente sin duda, que muy pronto él sufriría las consecuencias. Ninguno de los dos me respondió pero sus miradas eran de preocupación. Silvia hablaba claro pero yo no podía tomar partido por su argumento y considerar que era su esposo quien estaba en el error, puesto que los dos podrían entender que me dejaba llevar por la capacidad de convicción de ella y no por una razón objetivamente fundamentada. En ese momento me di cuenta de que sí había un problema que compartían y que permitía empezar a trabajar. Les dije que además del deseo de seguir juntos sintiéndose bien uno al lado del otro había otra cosa en la que también estaban de acuerdo: que ella estaba muy preocupada. Lucas subrayó mis palabras afirmando que efectivamente él creía que Silvia estaba demasiado preocupada. Continué diciéndoles que si Silvia consiguiera tranquilizarse respecto a la salud de Lucas probablemente la relación entre los dos mejoraría. Y le sugerí a él hacer un esfuerzo, un esfuerzo con el que sin duda ella se tranquilizaría. El esfuerzo consistía en realizar aquella analítica a la que hasta entonces se había negado. Lucas dijo, aunque con un cierto malhumor, que aceptaba hacerse una analítica y Silvia volvió a repetir que ella no quería separarse de él. Esta entrevista se había iniciado con dos motivos de consulta: «Ayude a que él deje de beber», por parte de Silvia y «Ayude a que ella deje de obsesionarse con la idea de que yo bebo», por parte de Lucas. Pero terminó con una demanda compartida por ambos: «Ayúdenos a que ella no tenga que seguir sufriendo por la salud de él».

\section{DEL MOTIVO DE CONSULTA A LA DEMANDA EN LA PSICOSIS}

Dependerá de lo compensado que esté un paciente psicótico en el momento de solicitar la consulta que tenga capacidad de concretar una demanda clara y coherente acerca de algún motivo de malestar. De hecho, fenomenológicamente, lo que caracteriza la psicosis es la ausencia de conciencia de enfermedad, lo que implica no reconocer necesidad ni motivo de pedir ayuda. 
A veces, cuando se atiende a un paciente psicótico, sobre todo en el caso de que la petición de consulta provenga de un familiar, se tiene la sensación de que por parte del sujeto no existe ninguna demanda. Si además goza de un período de cierta compensación, el psicólogo incluso puede llegar a creer que en realidad no existe ningún problema y que los familiares lo han traído por capricho. Cuando el paciente psicótico no formula ninguna demanda es necesario escuchar la de los familiares que le traen a la consulta. No obstante, que el paciente psicótico acepte consultar ya debe interpretarse como la manifestación de algún tipo de demanda.

Por definición, la psicosis es una enfermedad crónica, que puede cursar con brotes en los que el sujeto delira y alucina. Es decir, la psicosis es en sí misma un motivo de consulta, lo que hace falta es que alguien la articule en forma de demanda.

En la psicosis, se puede pensar que un indicador del éxito terapéutico es que el paciente consiga tomar consciencia de su enfermedad, es decir, que esté en condiciones de formular una demanda en relación a su delirio (14).

\section{DEL MOTIVO DE CONSULTA A LA DEMANDA EN EL TRATAMIENTO DE NIÑOS, PÚBERES Y ALGUNOS ADOLESCENTES}

Normalmente, en el caso de niños y púberes, es decir, de menos de 12, 13 o 14 años de edad, y también algunos adolescentes, cuando en ellos surge un problema son los padres, profesores o pediatras quienes lo detectan. El niño, en todo caso, puede sentir extrañeza o incluso culpa referida a algo de su comportamiento, pero raramente entiende que se trata de un problema psicológico personal. Por lo general son los padres quienes solicitan consultar y también ellos quienes traen al niño. Es decir, son ellos quienes autorizan que el psicólogo trate a su hijo. Por tanto, retomando el concepto de «agente terapéutico», podemos afirmar que en el tratamiento de niños, púberes y algunos adolescentes su acción está mediatizada por la parte subjetiva del niño, como también ocurre en el caso del tratamiento de personas adultas, pero además debe contar con la autorización de los padres o las personas responsables de él (15).

Es decir, en estos casos, la demanda principal debe provenir de los padres y ha de consistir en una petición de ayuda para su hijo. Cuando los padres consultan explicando que la demanda proviene de un profesor o del pediatra conviene que el psicólogo les ayude a entender el significado de esa demanda y que ellos puedan hacerla propia. Si no hay una demanda clara por parte de los padres, si no entienden exactamente por qué motivo llevan el niño a consultar y con qué objetivo, aunque el niño establezca un buen vínculo con el psicólogo, probablemente más tarde o temprano los padres interferirán activa o pasivamente, obstaculizando que el tratamiento se lleve a cabo correctamente. 
En cuanto a los niños, en la medida que no aciertan a entender que tienen un problema psicológico es probable que, de entrada, no puedan formular una demanda con la claridad propia de una persona adulta. Lo importante es que el niño que los padres han traido a tratamiento consiga reconocer que hay cosas de sí mismo, ya sean temores, comportamientos, etc., que le hacen sufrir y que entienda que el psicólogo puede ayudarle.

Hay adolescentes, traídos a consulta por sus padres, que acuden con una demanda propia diferente a la de ellos, relacionada con un sufrimiento personal. En tal caso es necesario tomarla como prioritaria pero sin desestimar la importancia de la demanda de los padres.

La madre de Elvira solicitó consultar preocupada por el comportamiento de su hija, de 15 años de edad. Según la madre, Elvira tenía un «carácter muy fuerte», motivo de continuas discusiones en casa y diversas expulsiones del instituto. Además, Elvira no mostraba ningún interés por nada, no tenía aficiones ni proyectos para su futuro. Los padres se separaron cuando tenía 4 años y con el padre la relación aún ha sido mucho más difícil. Al parecer, el padre de Elvira es una persona muy estricta, de costumbres que rozan con lo obsesivo. El motivo principal de conflicto entre Elvira y sus padres son los malos resultados escolares. Les preocupa que si no aprueba la ESO tendrá muchas dificultades en su futuro laboral. El padre inenta explicárselo y se enfada cuando considera que ella no muestra interés en estudiar, dando lugar a disputas que a veces han sido violentas. La madre, en cambio, para evitar graves enfrentamientos ha optado por no hablar de ese tema, aunque le preocupa mucho. Al terminar la entrevista se despidió asegurándome que Elvira acudiría el próximo día pero que dependería de la «empatía», que yo lograra que su hija quisiera seguir viniendo. Le respondí que por mi parte haría lo necesario para que pudiera haber «empatía» pero me quedé pensando que no sería fácil convencer a una chica de 15 años que no tiene interés por nada y que se violenta cuando le recuerdan las cosas que le van mal, de que necesita ponerse en tratamiento psicoterapéutico. A los pocos días de la entrevista con la madre acude Elvira. Le explico que su madre vino a hablar conmigo porque estaba preocupada por cosas que le pasaban en la escuela que la afectaban y porque creía que había perdido las ilusiones. Le pregunto qué le parece a ella que su madre consultara por ese motivo y responde que le es igual. «¿A ti te preocupa también, Elvira?», seguí interrogándole. «Sí, por culpa de que no sé callarme a veces en la escuela me castigan», respondió. "¿Qué quiere decir que no sabes callarte?», seguí. «Es que tengo un carácter muy fuerte y no sé detenerme cuando tengo que hacerlo y contesto mal o trato mal a los profesores, y por eso me castigan», dijo Elvira. Después de unos minutos de diálogo sin conseguir descubrir en ella alguna preocupación auténtica por los problemas que iba describiéndome, observé que sus ojos empezaban a lagrimear. «¡Ya está! -dijo- ¡No sé qué me ocurre! 
Cuando menos lo espero me pongo a llorar. Me pasa en todas partes. A veces estoy en clase y empiezo a llorar, sin saber por qué. Estoy hablando de fútbol o de básquet con algún amigo y sin venir a cuento me pongo a llorar. Entonces me preguntan qué me pasa y no sé qué reponder». Aproveché esa oportunidad para decirle: «Creo Elvira que, independientemente del motivo por el que tu madre vino a consultar conmigo, hay algo en lo que puedo ayudarte: a saber por qué te pasa eso».

Elvira se pronunció en una demanda de la que su madre no me había hablado. Entendí que era algo preocupante y molesto para Elvira y que esa demanda no se contradecía con el interés de su madre en que Elvira consultara. Decirle que podía ayudarla a entender por qué a veces se ponía a llorar era un modo de despertar el interés a seguir consultando en una chica adolescente traída por su madre cuyo problema era en un principio, no tener interés por nada.

\section{Agradecimientos}

Agradezco a Graziella Baravalle la supervisión de este artículo y al Dr. David Chesa la revisión técnica. Graziella Baravalle es psicoanalista, miembro docente de la Fundación Europea para el Psicoanálisis. El Dr. David Chesa es psiquiatra y asesor del área de investigación del Centro de Salud Mental de Sant Feliu de Llobregat.

\section{BIBLIOGRAFÍA}

1. López Herrero, L.S., Pérez, A., «La cara oculta de la tristeza», Rev. Asoc. Esp. Neuropsiq., 2003, nº 72, pág. 56.

2. Nasio, D., Cinco Lecciones sobre la Teoría de Jacques Lacan, Barcelona, Gedisa, 1995, pág. 126.

3. Moya Ollé, J., «La psicopatología: interés del diagnóstico para la clínica. El diagnóstico en psiquiatría», en Monografías clínicas en Atención Primaria, Aparicio, D. (comp.), Barcelona, Doyma, 1992.

4. Bleger, J., Temas de psicologia (Entrevista y grupos), Buenos Aires, Ediciones Nueva Visión, 1985, pág. 38.

5. Ortuño Sanchez-Pedreño, F., "Conducta de enfermedad y actitud del paciente hacia sus síntomas», en Manual del Residente de Psiquiatría, Cervera Enguix, S., et al, (comp.), Madrid, Smithkline Beecham, 1997.

6. Sierra, J.C., Buela-Casal, G., Garzón, A. y Fernández, M.A., «La entrevista clínica», en Manual de evaluación y tratamientos psicológicos, Buela-Casal, G., y Sierra, J.C. (comp.), Madrid, Biblioteca Nueva, 2001, pág. 45.

7. Strauss, M., «La primera consulta con el médico», en Monografias clínicas en Atención Primaria, Aparicio, D. (comp.), Barcelona, Doyma, 1992. 
8. Dor, J., Introducción a la Lectura de Lacan, Barcelona, Gedisa editorial, 1994, pags. 159-167.

9. Freud, S., La interpretación de los sueños, Obras Completas, Madrid, Biblioteca Nueva, 1983, pág. 689.

10. Lacan, J., Escritos 2, Madrid, Siglo veintiuno editores, 1975, págs. 665-675.

11. Cervilla Sánchez, F., "Demanda e institución en «El malestar en la cultura»», Rev. Asoc. Esp. Neuropsiq., 1999, vol. XIX, nº 70, pp. 237-244.

12. Tizón, J.L., Pellegero, N., Sáinz, F., Guadán, I., «El trabajo clínico de un Equipo de Salud Mental vinculado a la Atención Primaria de Salud con orientación psicosocial. Unas palabras sobre nuestros objetivos asistenciales globales», en Atención primaria en salud mental y salud mental en atención primaria, Tizón García, J.L. (comp), Barcelona, Doyma, 1992.

13. Bleger, J., Temas de psicología (Entrevista y grupos), Buenos Aires, Ediciones Nueva Visión, 1985, pág. 36.

14. Gracia, A., Psicoanálisis y psicosis, Madrid, Editorial Síntesis, 2001, págs. 29-31 y 189.

15. Winnicott, D.W., Clínica psicoanalítica infantil, Buenos Aires, Paidós Horme, 1980, págs. 14-19.

Pau Martínez Farrero

Doctor en Psicología, Centre de Salut Mental de St. Feliu de Llobregat

(Sagrat Cor, Serveis de Salut Mental)

Dirección:

C/. Tiro $6,9^{\circ}-5^{\circ}$

08035 Barcelona

Tel.: 932128023 . Móvil: 610652655 